\title{
Acidentes nas rodovias brasileiras nos últimos 10 anos: uma análise com dados abertos
}

\author{
Matheus K. G. Kageyama ${ }^{1}$, Nádia P. Kozievitch ${ }^{1}$, Rita C. G. Berardi ${ }^{1}$ \\ ${ }^{1}$ Universidade Tecnológica Federal do Paraná (UTFPR) \\ Av. Sete de Setembro, 3165 - Rebouças, Curitiba - PR, 80230-901, Brazil \\ matheus.kageyama@gmail.com, nadiap@utfpr.edu.br, ritaberardi@utfpr.edu.br
}

\begin{abstract}
Resumo. Analisar dados públicos com o intuito de gerar informações relevantes à sociedade é um tema que vem sendo discutido nos últimos anos, principalmente devido à facilidade de acesso a muitos desses dados que estão disponibilizados de forma aberta na Web. Tendo isso em vista, o objetivo desse trabalho é explorar os números de acidentes de trânsito e suas características, como localização, mortalidade, tipo de via, entre outros, com o intuito de prover análises que possam auxiliar na compreensão e caracterização dessas ocorrências, utilizando-se do auxílio de tecnologias para manipulação de informações geoespaciais.
\end{abstract}

\section{Introdução}

Segundo a Organização Mundial da Saúde (OMS), mais de 3400 pessoas morrem em acidentes de trânsito todos os dias e milhares ficam feridas ou incapacitadas ${ }^{1}$. Na classificação por causas de mortes, no ano de 2016, acidentes de trânsito ocupavam a $8^{\text {a }}$ posição no ranking mundial de mortes à frente de tuberculose e logo abaixo de diabetes, por exemplo².

No Brasil o número de acidentes nas rodovias brasileiras dos últimos anos também é alto, segundo dados da Polícia Rodoviária Federal (PRF) ${ }^{3}$. Apenas no ano 2017 foram registrados 89518 incidentes nas estradas, apesar de estatisticamente o número estar em queda quando comparado aos anos anteriores, ainda assim, em decorrência destes episódios 6245 pessoas faleceram.

Os dados apresentados acima são considerados de domínio público no Brasil e dessa forma podem ser adquiridos através de órgãos governamentais, como é o caso das informações que são utilizadas nesse trabalho (provenientes da Polícia Rodoviária Federal - PRF). A análise desses dados possibilita a resposta de perguntas como: "quais são os locais com maiores números de acidentes?" ou "quais os horários com maior número de acidentes?". Dessa forma investimentos em sinalização, orientação e fiscalização podem ser melhores aplicados pelas autoridades competentes. Assim sendo este trabalho tem por objetivo analisar os dados de acidentes fornecidos pela PRF em rodovias, com o intuito de observar padrões no que se refere a característica das ocorrências, como localidade, horário, número de feridos, condições da pista, entre outros.

Na seção 2 serão abordados trabalhos relacionados, na seção 3 será descrita a metologia utilizada para análise dos dados, na seção 4 serão apresentados os resultados

\footnotetext{
${ }^{1}$ http://www.who.int/violence_injury_prevention/road_traffic/en/

${ }^{2}$ http://www.who.int/en/news-room/fact-sheets/detail/the-top-10-causes-of-death

${ }^{3}$ https://www.prf.gov.br/portal/dados-abertos/acidentes/acidentes
} 
referentes a análise dos acidentes no Brasil. Na seção seguinte é apresentada a conclusão da análise com os dados de acidentes para o estado do Paraná e por último, na seção 6 é apresentada a conclusão do artigo.

\section{Trabalhos relacionados}

Devido ao grande número de acidentes com veículos, diversos estudos buscam compreender as causas desses eventos.

Um estudo realizado na Noruega [Gjerde et al. 2011], focou apenas na utilização de substâncias ilícitas, como álcool, drogas e medicamentos com substâncias psicoativas, e suas relações com acidentes de trânsito. Para este estudo foram utilizados dados de duas bases do governo: Estatísticas Norueguesas (contendo os dados de acidentes de trânsito) e o Instituto Norueguês de Saúde Pública (responsável pelos exames toxicológicos). O número de acidentes também foi alvo de investigação de jornais internacionais como a BBC que publicou a nota de [Kawaguti 2012] com o objetivo de identificar por meio de um estudo envolvendo entrevistas com familiares, orgãos públicos e a análise de dados de notícias e trabalhos relacionados, quais os principais motivos que levam ao alto indice de mortes nas estradas brasileiras. Os resultados apontaram que os números elevados de mortes são relacionados às más condições de direção, ocasionadas pelas más condições das rodovias; ao acesso limitado a serviços de emergência especializados; à legislação insuficiente e à inexperiência de motoristas. Concluiu-se ainda que a conscientização, a criação de leis mais rígidas e o apoio as famílias das vítimas é essencial para ajudar na diminuição destes indices.

O problema de acidentes de trânsito também foi analisado no trabalho de [Luís et al. 2016] onde os autores utilizaram a integração de dados abertos e técnicas de visualização para o transporte urbano da cidade de Curitiba-PR para diagnosticar os acidentes de trânsito na Cidade Industrial de Curitiba (CIC). Para realizar esta análise foi realizada a aquisição/caracterização de fontes de dados do SIATE (Secretaria da Segurança Pública e Administração) e do IPPUC (Instituto de Pesquisa e Planejamento Urbano de Curitiba) Por meio dos dados, descobriu-se que a maioria das colisões ocorre entre carros e motos e a maioria dos acidentados era do gênero masculino, sendo que a maioria dos acidentes era considerada grave, sem riscos para a vítima. Grande parte dos acidentes aconteceu à noite, sendo que o horário com maior número de acidentes foi das $18 \mathrm{~h}$ às $19 \mathrm{~h} 59$. Os pesquisadores identificaram ainda algumas estratégias como construir um banco de dados de lesões, incluir sinais de trânsito onde eles estão faltando, construir e melhorar a infra-estrutura disponível para pedestres e fornecer inspeções regulares para que os regulamentos sejam seguidos podem auxiliar na redução dos acidentes. Com o objetivo de melhorar a segurança no trânsito, o trabalho de [de Andrade L et al. 2014] mapeou as mortes no trânsito na rodovia brasileira BR277 para determinar os principais fatores ambientais que afetam as mortes no trânsito. Para realizar este mapeamento foi realizada uma análise espacial, onde foram especificados geograficamente os locais onde as colisões ocorreram e avaliados os padrões de distribuição por meio da visualização do mapa; uma análise Wavelet e uma análise de Kernel para decompor as séries de números de mortes em cada setor rodoviário da BR277; e uma análise do ambiente construído, para identificar as associações entre o ambiente construído e acidentes de trânsito. No período analisado foram notificados 379 acidentes, com 466 mortes no BR277 onde as fatalidades foram predominantemente masculinas. As duas faixas etárias com maior ocorrência de 
fatalidades foram de 31 a 50 anos e de 20 a 30 anos. Nos finais de semana houve mais mortes do que nos dias de semana com o sábado tendo a maior incidência. Observou-se que a maioria dos acidentes fatais ocorreu entre 18 horas e meia-noite. Com relação às condições climáticas,o céu limpo esteve presente durante a maior parte dos acidentes fatais seguido de tempo nublado. As fatalidades por quilômetro de rodovia simples versus pista dupla encontraram um aumento no número de fatalidades em estradas de pista dupla.

No trabalho de [Jardim et al. 2017] foram avaliadas 1013 ocorrências de acidentes de trânsito ocasionados por animais nas rodovias federais do estado de Pernambuco, entre os anos de 2012 e 2014. Para obtenção das variáveis utilizou-se o banco de dados do sistema operacional da PRF, o Siger 2. Foram utilizadas as variáveis: quantitativo de acidentes por ano, tipo de veículo, rodovia de ocorrência, tipo de pista, traçado da via, condições meteorológicas, fase do dia, tipo do solo (perímetro da via), sexo, idade dos condutores e estado físico das vítimas. Como resultado obteve-se que a maior ocorrência de acidentes aconteceu no ano de 2012 (40,1\%), ocasionados por automóveis (46,9\%), na BR $232(37,5 \%)$, em pista simples $(72,8 \%)$ com trechos em linha reta $(92,8 \%)$, em céu claro $(67,4 \%)$, fase de plena noite $(65,7 \%)$, e no perímetro rural $(72,2 \%)$. Predominaram os condutores do sexo masculino (86,3\%), com idade entre 18 a 40 anos $(54,5 \%)$ e $63,3 \%$ das vítimas foram classificadas como ilesas.

Outro trabalho que analisou o problema de acidentes de trânsito foi o de [Martins and Garcez. 2017].Foram utilizados os dados contidos no site da PRF e os dados presentes no Portal Brasileiro de Dados Abertos relacionados ao estado de Pernambuco. Os dados foram unificados numa base de dados única. Além da estatística descritiva, ainda foi criado um mapa viário de Pernambuco contendo os pontos em quem ocorreram acidentes, baseados na latitude e longitude fornecidas pela base dados. Para a criação desse mapa, foi utilizado um Sistema de Informação Geográfica (SIG). O estudo ocorreu com base em um banco de dados que abordou um total de 57.542 ocorrências, envolvendo 127.708 pessoas, entre os anos de 2007 até o mês de agosto de 2015. As variáveis que foram consideradas foram: perfil dos acidentes, perfil das pessoas, perfil dos veículos, perfil dos condutores, perfil dos acidentes graves e informação geográfica. O estudo foi fundamental para um diagnóstico mais preciso sobre as variáveis envolvidas nos acidentes. Alguns destaques sobre os acidentes foram identificados: a maiorias dos acidentes ocorrem no município de Recife, mas é Caruaru quem possui a maior parte de mortes, a BR com maior número de ocorrências é a BR-101/PE, é a sexta-feira o dia mais comum para acidentes, sendo o mês de dezembro o mais crítico, a falta de atenção é a causa mais frequente dos acidentes, destacando que a maiorias das causas é oriunda de erro humano, a colisão traseira o tipo mais comum, entretanto a colisão frontal a mais grave, pessoas entre 30 a 44 anos são os que mais se envolvem, sendo homens a maioria quando se trata do sexo dos envolvidos, automóveis são os veículos que mais se envolvem, porém são as motos que possuem consequências mais graves.

Em contrapartida aos trabalhos descritos anteriormente, o presente artigo busca uma análise mais geral, abordando todos os tipos de acidentes existentes na base utilizada (PRF), qual contém número superior de tipos de acidentes utilizados em trabalhos anteriores, além de levar em consideração todo o território brasileiro o que também difere dos antecedentes. 


\section{Metodologia}

Os dados utilizados nesse artigo estão disponíveis no formato CSV [Shafranovich 2005], no link "https://www.prf.gov.br/portal/dados-abertos/acidentes/acidentes" . Os dados foram inicialmente importados para uma base PostgreSQL [Momjian 2001].

Salienta-se que nem sempre os dados abertos estão disponíveis nos formatos ideais para o uso desejado ou estão totalmente corretos, tornando-se necessária a realização de conversões de formatos, importações dos dados e limpeza de informações inconsistentes. Como os dados provenientes da PRF não possuíam a localização latitudinal e longitudinal para as informações anteriores a 2017, foi necessário recorrer a API do OpenStreetMap ${ }^{4}$, no intuito de adquirir esses dados, tornando possível a geração de pontos geométricos na estrutura da extensão PostGIS, para a plotagem dos dados em mapas. Para manipulação de dados geoespaciais, a extensão PostGIS [Obe and Hsu 2011], adiciona suporte a objetos geográficos que em conjunto com a utilização do banco de dados relacional PostgreSQL, possibilita a geração de mapas de calor e cálculos de distâncias vetoriais.

Listing 1. Exemplo de consulta utilizada na análise dos dados.

\section{SELECT}

to_char (horario, 'HH24') hora, $\operatorname{COUNT}(*)$

FROM acidentes policia $_{-}$

WHERE ano BETWEEN 2007 AND 2017

GROUP BY hora ORDER BY hora;

Através da extração de dados da base da PRF com o auxílio de consultas SQL exemplificadas pelo código 1, tem-se por objetivo gerar gráficos e mapas de calor para ilustrar a distribuição dos acidentes dentro de suas diversas categorias.

\section{Análise dos acidentes no Brasil}

O número de acidentes em rodovias federais no Brasil tem decaído nos últimos anos conforme Figura 1, mas ainda assim no ano de 2017 foram registrados quase $100 \mathrm{mil}$ acidentes, dos quais ocasionaram 6245 mortes, conforme Figura 2.

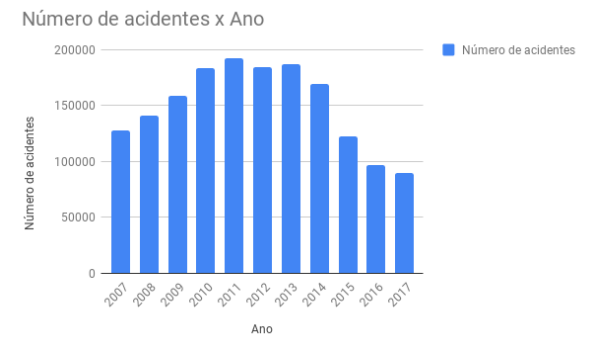

Figure 1. Número de acidentes no trânsito do Brasil por ano.

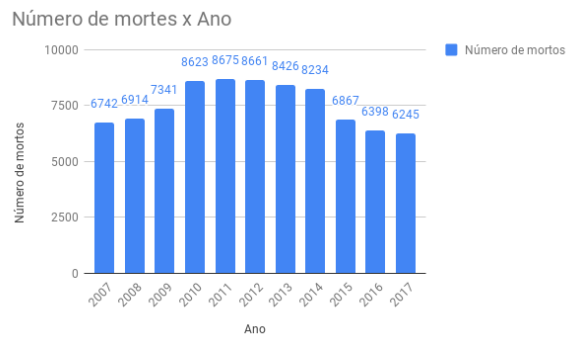

Figure 2. Número de mortes no trânsito do Brasil por ano.

Para demonstrar a importância do estudo desses dados, é possível relacionar a queda de acidentes na Figura 1 e a redução de número de mortes na Figura 2, com o

\footnotetext{
${ }^{4}$ https://www.openstreetmap.org
} 
aumento de severidade na "Lei Seca" no ano de 2012, Lei $N^{\circ} 12.760 / 2012^{5}$. A mesma outorga a aplicação de penalizações aos indivíduos que forem pegos com qualquer quantidade de álcool no sangue, diferente da lei anterior que possuía uma margem de tolerância, demonstrando que punições mais severas podem ajudar na diminuição do número de acidentes e consequentemente mortes.

Com o intuito de auxiliar nas tarefas de fiscalização das estradas é possível focar nos dias com maior número de acidentes e mortes. Com isso as Figuras 4 e 3 demonstram que os finais de semana e as sexta-feiras são os dias mais perigosos para se trafegar pelas estradas, provavelmente relacionados ao fato de que são os dias mais movimentados em rodovias federais, vias comumente utilizadas para viagens.

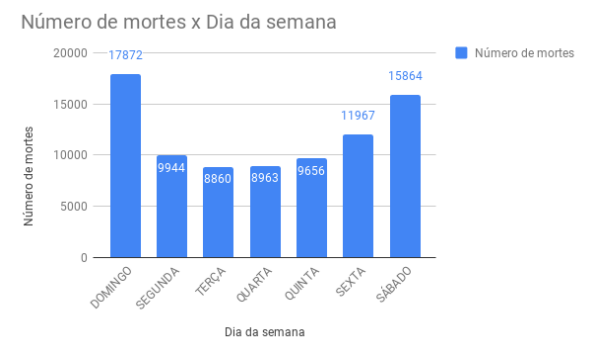

Figure 3. Número de mortes no trânsito por dia de semana.

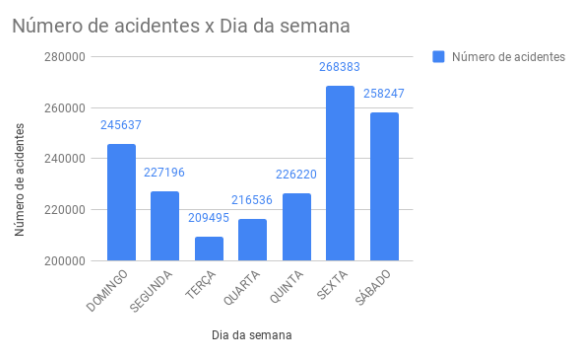

Figure 4. Número de acidentes por dia de semana.

Os horários do dia e meses também são fatores preponderantes no número de registros de ocorrências, conforme a Figura 5 e a Figura 6, os horários de "pico", em que ocorrem um maior número de pessoas deslocando-se entre locais como trabalho e casa é mais propício a acidentes. $\mathrm{O}$ mês de dezembro também registra um número relativamente maior de acidentes, provavelmente vinculado a ser um mês de férias escolares e assim muitas famílias acabam trafegando pelas rodovias em viagens.

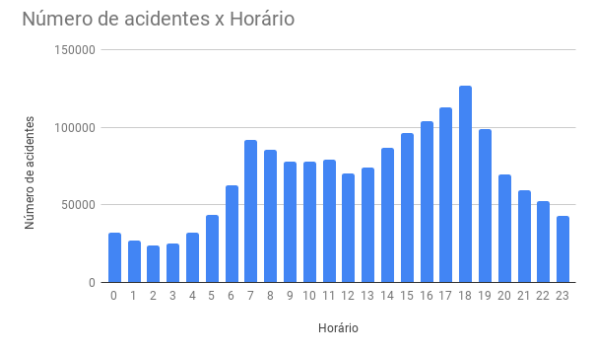

Figure 5. Número de acidentes por horário.

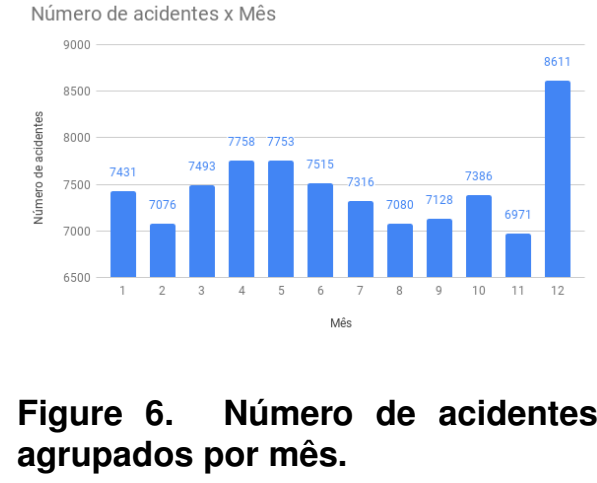

agrupados por mês.

A orientação dos motoristas também possui papel importante na redução desse número, segundo dados ilustrados pela Figura 7, que compreende o número de acidentes classificados por suas causalidades. A falta de atenção é o maior problema enfrentado. Uma melhor educação dos motoristas quanto à importância da atenção no trânsito e direção defensiva poderia reduzir esse número.

\footnotetext{
2018.

${ }^{5}$ http://www.planalto.gov.br/ccivil_03/_Ato2011-2014/2012/Lei/L12760.html. Acesso em: 14 nov.
} 


\section{Quantidade x Causa do acidente}

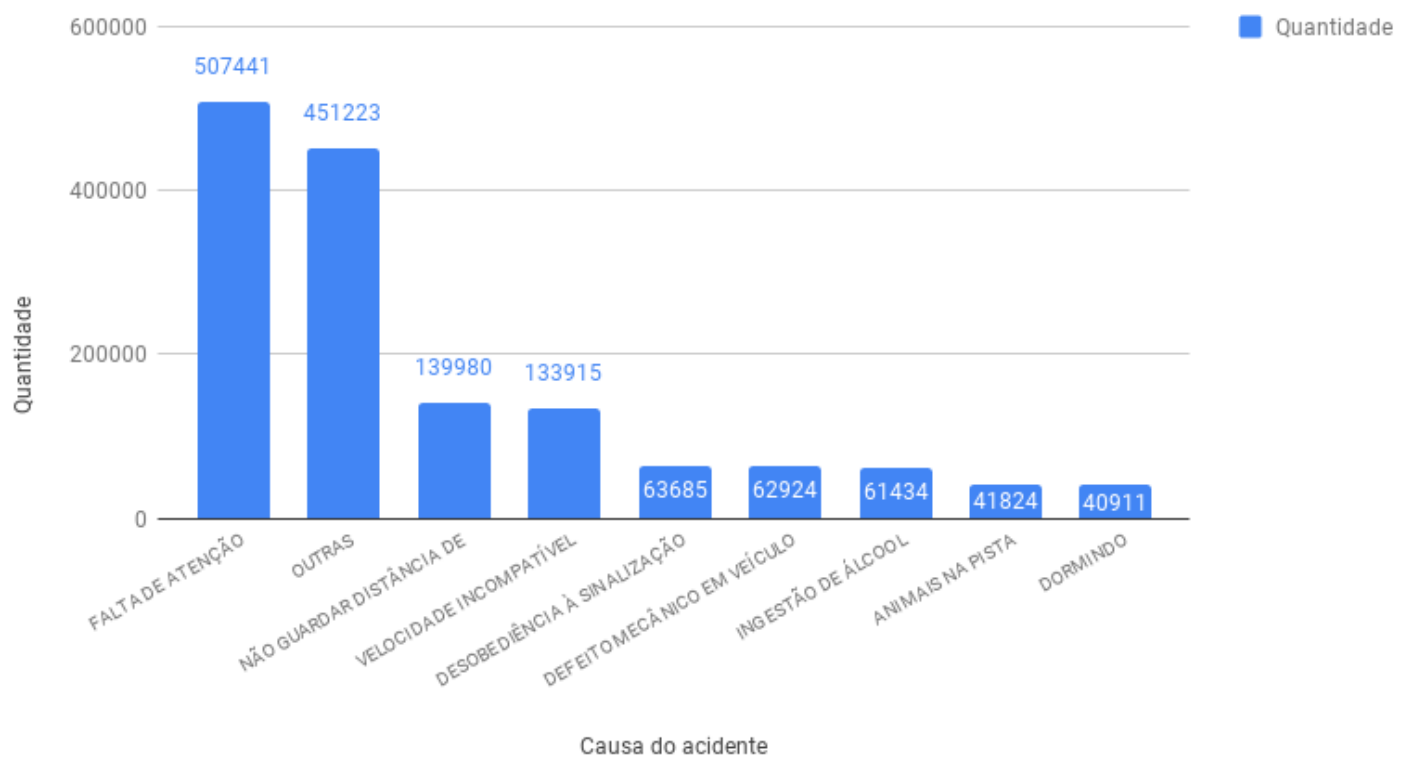

Figure 7. Maiores causas de acidentes.

\subsection{Distribuição de acidentes no Brasil}

Apesar dos acidentes estarem distribuídos por toda a extensão territorial brasileira, como ilustra a Figura 8, a quantidade de acidentes está concentrada em regiões específicas. Conforme a Figura 9, é possível visualizar que as regiões sudeste e sul concentram a maior parte das ocorrências registradas. Segundo dados da PRF, no ano de 2017 somente os estados da região sudeste e sul registraram 55427 registros, enquanto todos os outros registraram apenas 34091. Esses dados podem ser explicados quando se compara o tamanho da frota de veículos por região, segundo dados do Deparatamento Nacional de Trânsito (DENATRAN) de dezembro de $2017^{6}$, as regiões sul e sudeste registravam uma frota duas vezes maior que as outras 3 juntas com 66389279 veículos contra 30702677.

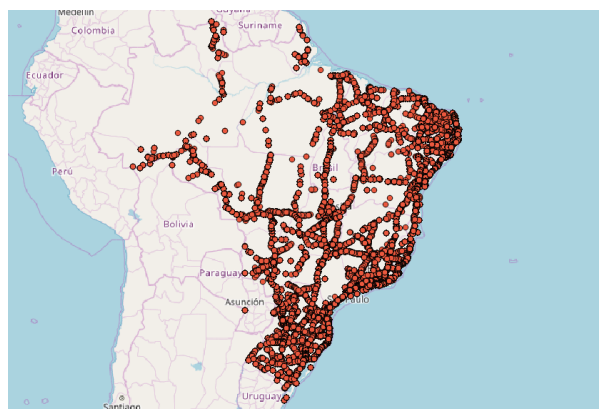

Figure 8. Pontos de acidentes no Brasil.

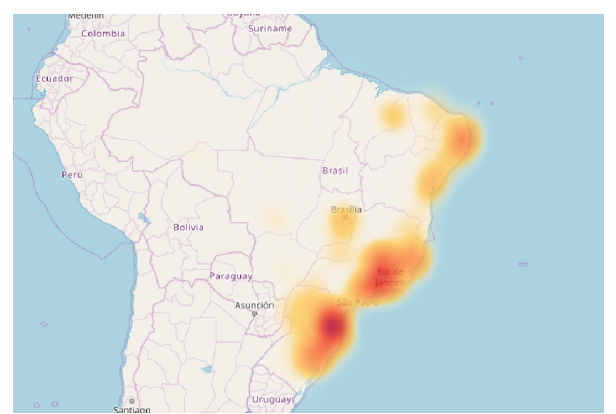

Figure 9. Mapa de calor utilizando peso por números de acidentes.

\footnotetext{
${ }^{6}$ http://www.denatran.gov.br/index.php/estatistica/610-frota-2017
} 


\section{Panorama dos acidentes nas rodovias federais do Paraná}

Nesta seção são analisados alguns números referentes ao estado do Paraná e suas relações e comparações com os dados apresentados anteriormente na seção 4. O estado, segundo dados do DENATRAN ${ }^{7}$, possui a terceira maior frota de veículos do País (número que ajuda a corroborar com a Figura 10) e também é o terceiro em número de acidentes.

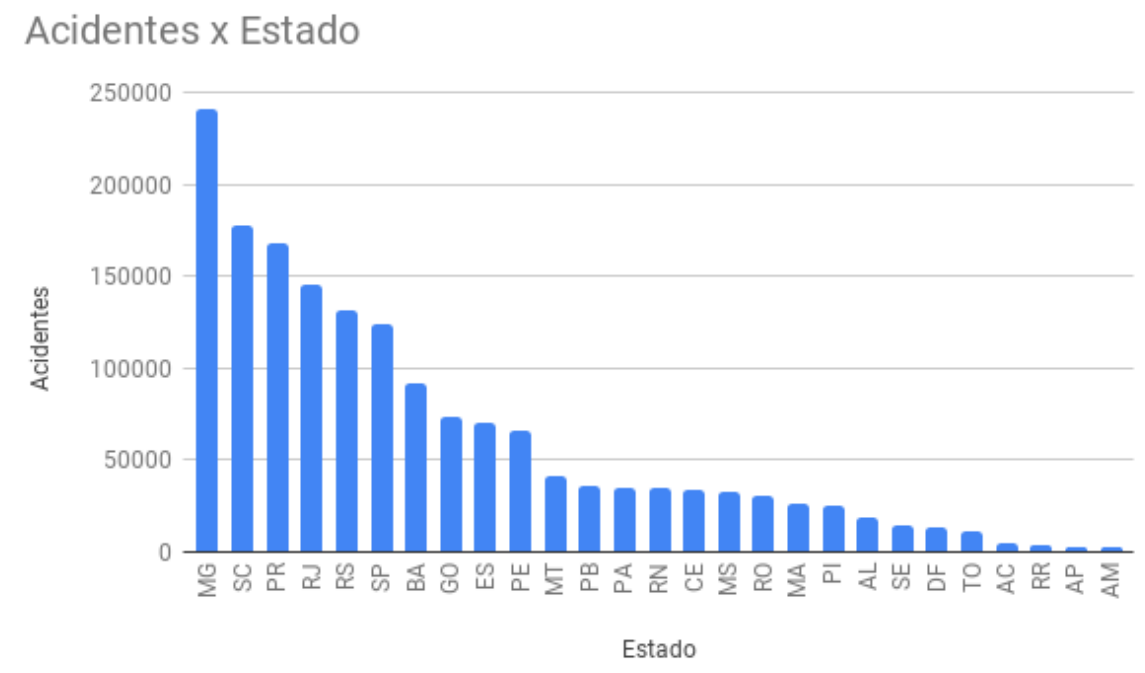

Figure 10. Acidentes por estado.

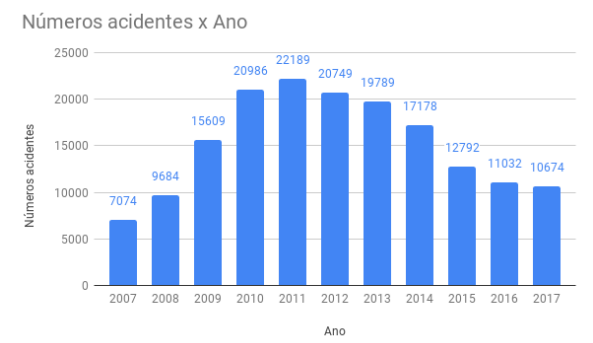

Figure 11. Acidentes no estado do Paraná por ano.

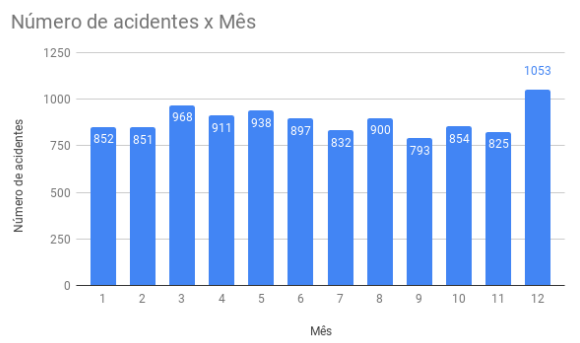

Figure 12. Acidentes no estado do Paraná por mês em 2017.

Na Figura 11, temos uma dispersão dos dados muito semelhante a apresentada na Figura 1, qual ilustra os número referentes a todo o país. Relação qual não se sustenta com a Figura 12, onde os números de acidentes por mês são muito mais relevantes no mês de Dezembro na Figura 6 do que na do estado do Paraná. Note que em relação à infraestrutura do país e do estado do Paraná, quando se analisa toda a nação percebese que os acidentes em pista simples acontecem mais frenquentemente que os acidentes em pista dupla ou múltipla, como indica a Figura 13. Entretanto, ao observar a Figura 14, verifica-se que os acidentes em pista dupla são muito mais frequentes no estado, sugerindo que não necessariamente uma melhor infraestrutura de pista está diretamente ligada à quantidade de acidentes.

\footnotetext{
${ }^{7}$ http://www.denatran.gov.br/index.php/estatistica/610-frota-2017
} 


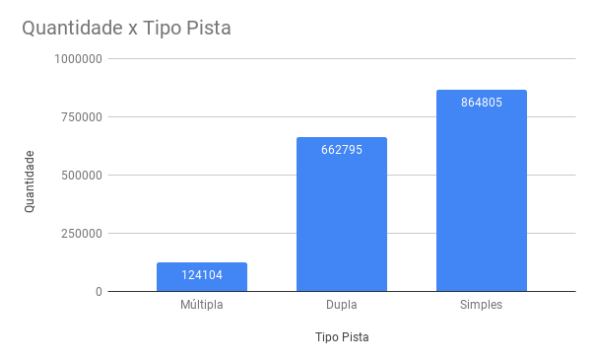

Figure 13. Acidentes por tipo de pista no Brasil.

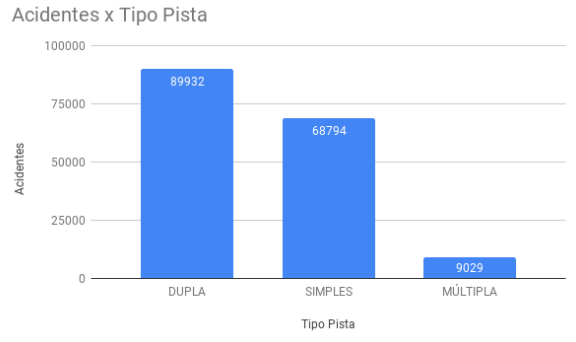

Figure 14. Acidentes no estado do Paraná por tipo de pista.

A Figura 15 apresenta a distribuição de acidentes por toda a extensão territorial, mas quando observa-se a Figura 16, percebe-se que existe uma forte concentração de acidentes em locais específicos, principalmente a capital do estado Curitiba, e as outras duas regiões mais populosas, abrangendo Londrina/Maringá e as estradas até Foz do Iguaçu, local muito frequentando por pessoas em trânsito para turismo ou acesso à fronteira com o Paraguai e Argentina.

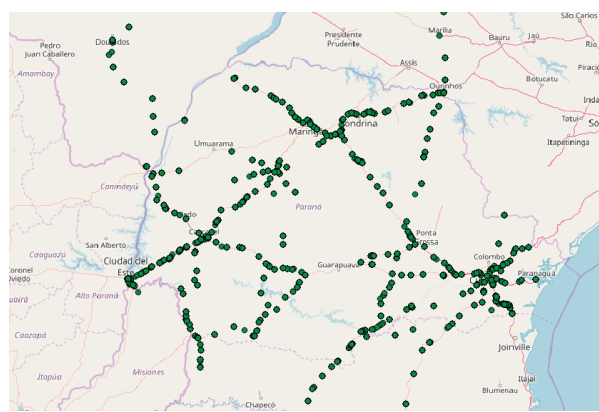

Figure 15. Localização de acidentes no Paraná.

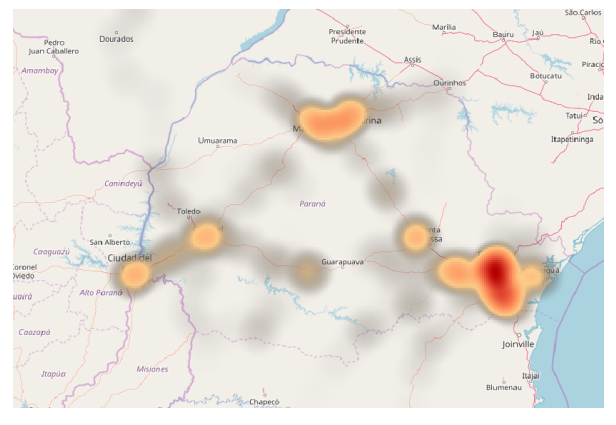

Figure 16. Mapa de calor no Paraná, com intensidade por número de acidentes.

Vale a pena notar que alguns pontos na Figura 15 não estão exatamente dentro do estado, devido ao fato de que os registros são inseridos no sistema manualmente, ocorrendo equívocos na hora do operador cadastrar as informações.

\section{Conclusão}

Como explorado neste trabalho, o estudo das informações disponibilizadas pelos órgãos públicos, pode gerar contribuições interessantes à sociedade. Através da manipulação de dados para visualização de informações como, meses com maior número de acidentes, localização onde os mesmos ocorrem, as principais causas e inclusive os horários mais críticos. Dessa forma ações pelos órgãos competentes podem ser julgadas, com maior conhecimento e propriedade, na tentativa de alcançar melhores benefícios e reduzir gastos ao focar nos problemas corretos.

Este trabalho apresentou uma análise genérica em termo de quantidade de categorização para os dados e também em relação ao escopo territorial, com o objetivo de servir para futuras análises comparativas entre outros estudos, através de dados que abrangem maiores categorias de acidentes e todo o território nacional. 
Através das informações manipuladas neste trabalho pode-se observar que horários de pico entre 07:00 às 08:00 e 17:00 às 19:00 são horários mais propícios a ocorrência de um acidente, assim como a sua concentração histórica no mês de dezembro. Fatores como falta de atenção, imprudência de motoristas, a velocidade e a não manutenção de uma distância mínima de segurança são fatores preponderantes nas causas de acidentes.

\section{References}

de Andrade L, JR, V., and et al., R. C. (2014). Brazilian road traffic fatalities: a spatial and environmental analysis. volume 9.

Gjerde, H., Normann, P. T., Christophersen, A. S., Samuelsen, S. O., and Mørland, J. (2011). Alcohol, psychoactive drugs and fatal road traffic accidents in norway: A case-control study. Accident Analysis \& Prevention, 43(3):1197 - 1203.

Jardim, J. M. M., da Silva Júnior, R. A., Pascoal, I. C., da Fonseca Oliveira, A. A., and Junior, J. W. P. (2017). Análise dos acidentes de trânsito ocasionados por animais nas rodovias federais do estado de pernambuco. Revista Medicina Veterinária, 11(1):7684.

Kawaguti, L. (2012). Brazil's struggle to cut deaths on chaotic roads. $B B C$.

Luís, I. C., Kozievitch, N. P., and Gadda, T. M. C. (2016). Traffic accident diagnosis in the last decade - a case study. In 2016 IEEE 19th International Conference on Intelligent Transportation Systems (ITSC), pages 1678-1683.

Martins, M. A. and Garcez., T. V. (2017). Análise descritiva dos acidentes nas rodovias federais de pernambuco (2007-2015). In Enegep - XXXVII ENCONTRO NACIONAL DE ENGENHARIA DE PRODUÇÃO.

Momjian, B. (2001). PostgreSQL: introduction and concepts, volume 192. AddisonWesley New York.

Obe, R. and Hsu, L. (2011). Postgis in action. GEOInformatics, 14(8):30.

Shafranovich, Y. (2005). Common format and mime type for comma-separated values (csv) files. 